\title{
Prenatal Diagnosis in France: Between Regulation of Practices and Professional Autonomy
}

\author{
ISABELLE VILLE * \\ Centre d'Etude des Mouvements Sociaux (CNRS FRE 2023 - INSERM U1276 - EHESS), \\ Paris, France
}

\begin{abstract}
Prenatal diagnosis (PND) was introduced in France in the 1970s on the initiative of medical researchers and clinicians. For many years the regulation of practices was self-imposed, decentralised and idiosyncratic. The advent of 'therapeutic modernity' in the 1990s gave rise to an ethical, legal and scientific framework designed to homogenise PND at a national level, with the creation of multidisciplinary centres (CPDPN) and the Agence de la biomédecine. This article first recovers the history of PND in France. It then compares the activities of two CPDPNs, using ethnographic fieldwork and by analysing national quantitative data compiled by the Agence. It argues that the official policy of nationally homogeneous practices is not born out in practice, at the local level. This lack of homogeneity is most apparent in the number of authorisations for pregnancy termination due to foetal malformation, which varies considerably from one centre to another. Rooted in local culture, this variation relates to organisational methods, decision-making processes and variable levels of tolerance towards the risk of disability. Foetal medicine practitioners, thus, maintain a certain amount of autonomy that is collective rather than individual and that is reflected in the particular 'identity' of a given centre.
\end{abstract}

Keywords: France, Prenatal diagnosis, Medical termination of pregnancy, Professional regulation, Health technology in practice, Disability prevention

\footnotetext{
* Corresponding address: Centre d'Etude des Mouvements Sociaux, Ecole des Hautes Etudes en Sciences Sociales, 54 boulevard Raspail, 75006 Paris - France. Email address for correspondence: Isabelle.ville@ehess.fr The project was funded by the Agence Nationale de la Recherche. In 2010 the project was granted authorisation by the CEEI (Institutional Review Board) registered with the NIH's OHRP (Office of Human Research Protection): IRB0000388 - FWA00005831. First and foremost I would like to thank all of the healthcare professionals who helped with this research. My thanks as well to Caroline Rusterholz and Jesse OlszynkoGryn for giving me the opportunity to present a former version of this paper at the University of Cambridge on 6-7 September 2016, Ilana Löwy and two anonymous reviewers for their careful re-reading of a previous version of the manuscript and their pertinent remarks, and Christopher Hinton for his translation from French.
} 


\section{Introduction}

As in many other European countries, prenatal diagnosis (PND) was introduced in France in the 1970s, marking the transition from eugenics to genetic counselling. ${ }^{1}$ It was on the initiative of a small number of reproductive scientists and geneticists familiar with international research practices. For many years they enjoyed substantial autonomy, selfregulating their practices as a professional organisation funded by the French national health system. In the 1980s, the international context surrounding medical research changed drastically with the rise of bioethics and of patient-led campaigning that led to the regulation of medical and scientific practices. As shown by French sociologist, Nicolas Dodier, this period saw a shift away from the 'clinical tradition' model of healthcare, that privileged the personal authority of practitioners in patient-related decision-making, towards the 'therapeutic modernity' model of standardised, evidence-based medicine and the institutionalisation of bioethics. ${ }^{2}$ During genetic counselling consultations, 'in contrast with traditional clinical encounters, emphasis was placed on the separation between the objective analysis of the situation and the choice between existing options regarding reproductive life and medical intervention'. ${ }^{3}$ This shift went hand in hand with a number of transformations: the decline of medical paternalism and the rise of the patient as an active decision maker; ${ }^{4}$ the introduction of a logic of 'choice' and reproductive autonomy into the clinical relationship ${ }^{5}$ and, not least, the rise of the disability rights movement, which reframed disability as socially constructed, ${ }^{6}$ and which criticised PND for discriminating against disabled people. ${ }^{7}$ As a result of all these changes, PND practices became increasingly regulated - through legislation and by recommendations from national and international organisations.

In 1994, France passed a law on bioethics, of which one of the aims was to regulate PND activities. ${ }^{8}$ The government set up a nationwide network of multidisciplinary PND centres (CPDPNs), to provide expertise and to take responsible for implementation. In 2001, the French minister for health set up the Comité National Technique de l'Echographie

\footnotetext{
${ }^{1}$ Heike I. Petermann, Peter S. Harper and Susanne Doetz (eds), History of Human Genetics: Aspects of Its Development and Global Perspectives (Cham: Springer, 2017).

${ }^{2}$ Nicolas Dodier, Leçons politiques de l'épidémie de sida (Paris: EHESS, 2003). See also Nicolas Dodier and Janine Barbot, 'Autonomy and Objectivity as Political Operators in the Medical World: Twenty Years of Public Controversy about AIDS Treatments in France', Science in Context, 21 (2008), 403-34.

3 Jean-Paul Gaudillière, 'A comparative and social history of genetic counselling?'. in Petermann et al., op. cit. (note 1), 570.

4 Janine Barbot, 'How to Build an "Active" Patient? The Work of AIDS Associations in France', Social Science \& Medicine, 62 (2006), 538-51.

5 Annemarie Mol, The Logic of Care: Health and the Problem of Patient Choice (London and New York: Routledge, 2008). Alex Mold, Making the Patient-Consumer: Patient Organisations and Health Consumerism in Britain (Manchester: Manchester University Press, 2015). Diana B. Paul, Controlling Human Heredity: 1865 to the Present (Amherst, NY: Humanity Books, 1995).

${ }^{6}$ Among others: Mike Oliver, Understanding Disability: From Theory to Practice (New York: St Martin's Press, 1996); Colin Barnes and Geof Mercer, Exploring Disability (Cambridge: Polity Press, 2010).

${ }^{7}$ Among others: Erik Parens and Adrienne Asch, Prenatal Testing and Disability Rights (Washington: Georgetown University Press, 2002); Marsha Saxton, 'Disability rights and selective abortion', in R. Solinger (ed.), Abortion Wars: A Half Century of Struggle, 1950-2000 (Berkeley and Los Angeles: University of California Press, 1997), 374-95; Linda M. Ward. 'Whose Right to Choose? The "New" Genetics, Prenatal Testing and People with Learning Difficulties', Critical Public Health, 12 (2002), 187-200; Lisa Blumberg, 'The Politics of Prenatal Testing and Selective Abortion', Sexuality and Disability, 12 (1994), 135-53.

${ }^{8}$ Law no. 94-654 of 29 July 1994 relating to the donation and use of elements and products of the human body to medical assistance for procreation and to prenatal diagnosis (JORF (Journal officiel de la République française) no. 175 of 30 July 1994, 11060).
} 
(National Technical Ultrasound Committee) to define the brief for ultrasound screening and for diagnosis. In 2004, amendments to the law on bioethics ${ }^{9}$ created the Agence de la biomédecine (ABM) to govern and monitor the activities of CPDPNs and of diagnostic laboratories, and to come up with guidelines and recommendations, including some that were based on ethical considerations. Focusing on the decision-making autonomy of patients obliged practitioners to inform couples, while at the same time obeying a principle of non-directiveness that transfers responsibility for the decision to women and families, which is sometimes difficult to achieve. Other recommendations, from the biomedical domain, were based on the current state of scientific knowledge; for example, the points to be covered during an ultrasound scan or the calculation of risk associated with given ultrasound soft markers. Furthermore, the courts became involved in the regulation of PND from the 2000s. ${ }^{10}$ Media coverage of high-profile malpractices proceedings considerably increased the concerns of practitioners regarding the threat of legal action. ${ }^{11}$

Historians have examined the dissemination of techniques in different countries. Generally linked to abortion legislation, they mark the shift from laboratory to clinic and from eugenics to genetic counselling. Initially, the latter was essentially a question of vocabulary. In the 1960s, eugenics was no longer well received and the expression 'human genetics' was used to refer to the same ideas and practices, focused on the collective good and the prevention of disability. However, with the emergence of genetic counselling, responsibility for decisions relating to reproduction gradually shifted over to women and couples, following the principles of autonomy and non-directiveness. ${ }^{12}$ It was not that geneticists had abandoned the eugenics programme, they had seen that the couples who used their services made 'rational' decisions, realising of their own accord that there was convergence between private interests and the interests of the population as a whole, without needing to be directed. ${ }^{13}$

Social scientists have examined practices associated with PND and their effects, including the moral dilemmas faced by women ${ }^{14}$ and by practitioners. ${ }^{15}$ Others have looked at counselling practices, at the way in which information on risks is provided and understood by women, and at whether or not medical practitioners comply with the principle of non-directiveness. ${ }^{16}$ The autonomy of women and couples, as promoted

${ }^{9}$ Law no. 2004-800 of 6 August 2004 relating to bioethics (JORF no. 182 of 7 August 2004, 14040).

${ }^{10}$ See L'affaire Perruche and the decision of the French Supreme Court (Cour de cassation) 17 November 2000, that generated a controversy dividing lawyers and disabled persons associations. Olivier Cayla and Yan Thomas, Le droit de ne pas naître: A propos de l'affaire Perruche (Paris: Gallimard, 2002).

${ }^{11}$ Danielle Moyse and Nicole Diederich, 'Prenatal Screening for Anomalies: Between Clinical Finality and Selective Finality', Scandinavian Journal of Disability Research, 9 (2007) 254-77.

12 See Petermann et al., op. cit. (note 1); Ilana Löwy, Imperfect Pregnancies: A History of Birth Defects and Prenatal Diagnosis (Baltimore: Johns Hopkins University Press, 2017); Paul, op. cit. (note 5).

${ }^{13}$ Paul, op. cit. (note 5).

${ }^{14}$ Rayna Rapp, Testing the Women, Testing the Fetus. The Social Impact of Amniocentesis in America (New York, London: Routledge, 2000); Barbara Katz-Rothman, The Tentative Pregnancy: Prenatal Diagnosis and the Future of Motherhood (New York: Penguin books, 1987).

15 Jean-Christophe Weber, Catherine Allamel-Raffin, Thierry Rusterholtz, Isabelle Pons and Isabelle Gobatto, I. 'Les soignants et la décision d'interruption de grossesse pour motif médical: entre indications cliniques et embarras éthiques', Sciences Sociales \& Santé, 26, 1 (2008), 93-120; Clare Williams, Priscilla Alderson and Bobbie Farsides, op. cit. (note 8); Monique Membrado, 'La décision médicale entre expertise et contrôle de la demande: le cas des interruptions de grossesse pour motif thérapeutique', Sciences Sociales et Santé, 19, 2 (2001), 31-61.

${ }^{16}$ Angus Clarke, 'The evolving concept of non-directiveness in genetic counselling, in P. Harper and Doetz (eds), op. cit. (note 1), 541-566; Nete Schwennesen, Mette Nordahl Svendsen and Lene Koch, 'Beyond Informed Choice: Prenatal Risk Assessment, Decision-making and Trust', Clinical Ethics, 5 (2010), 207-216; Lynda M. Hunt, Heide Castaneda and Katherine de Voogd, 'Do Notions of Risk Inform Patient Choice? Lessons from a Study of Prenatal Genetic Counselling', Medical Anthropology, 25 (2006), 193-219. 
in counselling practices, has been widely examined. These studies show that a neutral attitude can cause women to feel abandoned. ${ }^{17}$ Several authors have found this liberal orientation, which places responsibility for decision-making on the private sphere, to be an instrument of governmentality, ${ }^{18}$ of 'biocitizenship' ${ }^{19}$ or of a 'new eugenics' based on citizen demands. ${ }^{20}$ But while couples' decision-making autonomy has been the object of much research, few works have examined the autonomy of practitioners in current PND practices, or the way in which autonomy has been impacted by changes in clinical practices. This article will attempt to redress this gap by offering a detailed analysis of PND practices, rooted in the French local socio-political context that I briefly described above. By observing staff activities in CPDPNs, it examines comparatively how French PND practitioners have been coping with the rapid change that saw the shift from the total autonomy of genetic counselling practices to a legal and institutional framework designed to make them homogeneous. The first section of the article explores the historical context for the establishment of PND practices in France, from the unregulated early 1970s to the implantation of the national regulatory framework introduced by the government in the 1990s and 2000s. It is based on interviews and on a witness seminar organised in 2012 with France's PND pioneers. ${ }^{21}$ The second section analyses contemporary practices, focusing on decision-making in relation to authorisations by French PND centres for pregnancy termination due to foetal malformation. To do so, I combine two types of sources. To assess the homogeneity of practices targeted by the regulatory framework, I use administrative and quantitative data on the activity of each centre. I complemented these sources with an ethnography of work organisation and of the processes of deliberation found in two selected centres - one in Paris, the other in the provinces. The inductive analysis of the ethnographic data reveals differences in decision-making processes and attitudes towards PND, topics that are usually absent in archival sources. This analysis shows major differences in the way practitioners interpret official guidelines, define their missions and organise their work in such a way as to maintain relative autonomy.

\section{The Establishment of Prenatal Diagnosis in France}

The first positive prenatal diagnoses were made in France in 1970, following the development of a successful foetal cell culture technique by geneticist Joëlle Boué and bacteriologist André Boué, a Paris-based husband-and-wife team. ${ }^{22}$

\section{Infrastructure and Technologies Under Practitioner Control}

Although abortion was still illegal at that time in France, so-called therapeutic abortion was allowed from 1939 under a change to the Code de la Famille in cases where the pregnancy endangered the mother's life. ${ }^{23}$ From the 1950s, the dispositif used by

\footnotetext{
17 Clarke, ibid. .

${ }^{18}$ Michel Foucault, Dits et Ecrits, Tome III: 1976-1978 (Paris: Guallimard).

${ }^{19}$ Maria Björkman and Anna Tunlid, 'The establishment of genetic counselling in Sweden: 1940-80. in Petermann, Harper and Doetz (eds), op. cit. (note 1), 339-366.

${ }^{20}$ Paul op. cit. (note 5).

${ }^{21}$ For the full transcription of the witness seminar: http://anr-dpn.vjf.cnrs.fr/.

${ }^{22}$ Simone Gilgenkrantz and E.M. Rivera, 'The History of Cytogenetics: Portraits of Some Pioneers', Annales de Génétique, 46, 4 (2003), 433-42.

${ }^{23}$ Although the decree law of 29 July 1939 is one of the most repressive texts on abortion, it legalises abortion under the sole condition that it saves the mother's life; it takes up the device developed by doctors themselves in 1852, the date on which the Académie de Médecine recognised abortion as a therapeutic act. This measure was
} 
obstetricians who practiced such abortions was later expanded to include other indications, such as German measles and toxoplasmosis. ${ }^{24}$ The chromosomal anomalies and metabolic diseases discovered through PND were added to the list of indications, without any change in procedure and without practitioners having to worry about the authorities.

This context enables the understanding of the reasons why the PND pioneers did not take part in public debates on abortion that raged in 1970s France; several of them confirmed this during the interviews:

I never wanted to be part of any of those movements (. . .) We certainly didn't hide away, but we never went to any opposition or public meeting or anything like that. (...). We kept to our technical, scientific field. I think we made the right choice because that's why people trusted us (André Boué, extract from an interview with Marianne Bach in 2001). ${ }^{25}$

The therapeutic abortion dispositif sufficed to meet their needs. Indeed, they were not all in favour of the deregulation of abortion, as can be seen in this extract from a speech given by Professor Hervet, a gynaecologist-obstetrician, during the Entretiens de Bichat sessions in $1970:^{26}$

To give just one example, nowadays in many cases of German measles contracted at the beginning of a pregnancy (...) an expert can be found to sign the abortion protocol (...). Medical abortions are agreed with a liberalism that is increasing from one day to the next, a liberalism that it is neither necessary nor possible to enclose in new legislative devices.

The link between the history of genetic counselling and women's mobilisation for the right to abortion, a major issue in many countries, ${ }^{27}$ would not appear to be pertinent to the case in France, although the fact that the techniques were available would at some stage probably have led to a broader law on foetal indications. In 1970, draft legislation was put forward in this respect but was immediately rejected on the basis that it did not resolve the public health problem of illegal abortions. ${ }^{28}$

However, the government's delegation of the matter of reproduction to scientists and doctors is demonstrated by the specific nature of the French law. ${ }^{29}$ While most countries that had legalised abortion had restricted the practice to the term of foetus viability, French legislation clearly distinguished between two reasons. On the one hand, it set the term beyond which a voluntary termination (IVG) could no longer be performed at ten weeks

in fact intended to contain what was starting to be denounced as abuse. Article 87 states that in order for the medical practitioner to intervene, the mother's life must be in grave danger. He must then seek the opinion of two consulting doctors, one of whom must be chosen from the civil court's list of experts. (...) during a consultation, the two experts must establish that the mother's life may only be saved by a termination of pregnancy'. On abortion in France: Jean-Yves Le Naour and Catherine Valenti, Histoire de l'avortement. 19ème-20ème siècle (Paris: Le Seuil, 2003); Fabrice Cahen, Gouverner les moeurs, la lutte contre l'avortement en France, 1890-1950 (Paris: Ined, 2016).

24 The term dispositif is taken from Michel Foucault, Surveiller et punir (Paris: Gallimard, 1975).

25 Among these 'people', André Boué mentions Simone Veil, then minister for health. It is important to note that André and Joëlle Boué and their team were working under Robert Debré, a leading mandarin, member of the Resistance and politician, who had notably initiated France's hospital reform in 1958. I would like to thank my colleague, Marianne Bach, for sharing this interview, which took place a decade prior to my team's work.

${ }^{26}$ E. Hervet, 'Vers l'avortement libre': Entretiens de Bichat. Gynécologie (1970), 337-42.

27 See Petermann et al, op. cit. (note 1); Löwy, op. cit. (note 13).

${ }^{28}$ Backed by Senator Peyret, it authorised abortion in cases where the mother's health or life were threatened, where there were proven foetal malformations, where pregnancy had resulted from rape or incest, and where the mother or father suffered from mental deficiency.

${ }^{29}$ Law no. $75-17$ of 17 January 1975 relating to voluntary termination of pregnancy (JORF, 18 January 1975, 739). 
of pregnancy, which is very restrictive compared to other countries.$^{30}$ On the other hand, in accordance with the requests of PND pioneers, it imposed no limits on medical termination of pregnancy (MTP): ${ }^{31}$

You know that our law does not provide for any term limit (for MTP) That was my doing. (...) When Simone Veil made her law, she asked for my advice on the medical aspects. (...) We worked very closely with our colleagues abroad. They had all set a term limit and this was creating all sorts of problems. If you were there the week before, you could terminate the pregnancy, but one week later you could not. I explained this to Simone Veil. I said that the ideal solution was to have no limit because otherwise there'd be terrible situations. She said 'That's what I'll do' (André Boué, extract from an interview with Marianne Bach in 2001).

Once the technique had been perfected, the dissemination of PND practices was facilitated by recourse to another dispositif, one developed for the neonatal diagnosis of phenylketonuria (PKU), introduced in France in $1966 .{ }^{32}$ Based on a nationwide network of maternity centres and diagnostic laboratories, this dispositif was managed by an association of geneticists (AFDPHE - Association Française pour le Dépistage et la Prévention des Handicaps de l'Enfant). An initial experiment, carried out between 1974 and 1977 in five university towns, gave pregnant women aged forty and older the opportunity to have an amniocentesis to examine the foetal karyotype; the detection of Down syndrome automatically led to an abortion. ${ }^{33}$ In 1980, an agreement signed by the AFDPHE, the Association des centres de biologie prénatale and the Caisse nationale d'assurance maladie set the fee for the procedure and the age threshold at thirty-eight, with the French health service reimbursing the AFDPHE. Women therefore had nothing to pay up front. ${ }^{34}$

Realising early on that targeting women aged thirty-eight and over led to only 20 per cent of Down syndrome foetuses being diagnosed, French researchers focused their efforts on 'women at added risk'. ${ }^{35}$ Screening then became possible through the use of maternal serum markers, a procedure tested by the AFDPHE in the 1990s and reimbursed by the French health service from 1997 onwards. Merging into existing dispositifs, French researchers, geneticists and biologists thus quietly set about introducing PND in France, using a model that some described as professional self-regulation. ${ }^{36}$

${ }^{30}$ Law no. 2001-588, updated the 1975 Veil law (JORF no. 0156 of 7 July 2001, 10823). It extended the term allowed for voluntary termination of pregnancy to twelve weeks of pregnancy.

${ }^{31}$ Löwy, op. cit. (note 13). The US 1973 law did not initially put time limits on 'abortion on demand', but such limits were later established by state legislation. In the UK, such a limit was fixed at twenty-four weeks in 1967. The Austrian law, also passed in 1975, makes the same distinction: Katja Geiger and Thomas Mayer, 'The establishment of human genetic counselling in Austria in the 1970s in between the establishment of human genetic and eugenic indication of abortion', in Petermann et al, op. cit. (note 1).

32 Phenylketonuria (PKU) is a rare inherited condition associated with profound mental retardation that can be prevented through the early implementation of a diet. For the history of neonatal screening for PKU, see Diane B. Paul and Jeffrey P. Brosco, The PKU Paradox: A Short History of a Genetic Disease (Baltimore: Johns Hopkins University Press, 2013).

${ }^{33}$ Our interviews with the pioneers provided more detailed information on the procedure introduced in the various centres. An information consultation was organised, usually with a geneticist, prior to any amniocentesis; effective performance of the latter was conditional upon an oral undertaking to terminate the pregnancy in the case of a positive diagnosis.

${ }^{34}$ Marie-Mouise Briard, 'Organisation du diagnostic prénatal en France', in M. Dommergues, S. Aymé, P. Janiaud and V. Seror (eds), Diagnostic prénatal: Pratiques et enjeux (Paris: Inserm, 2003).

35 André Boué, Bulletin de l'Association Française pour le Dépistage et la Prévention des Handicaps de l'Enfant, 1981. Their risk was admittedly increased, but they procreated less. Karyotype analysis could not be expanded, partly due to its financial cost, but also and above all due to its consequences in terms of miscarriage, estimated at 1 per cent.

36 Jean-Pierre Moatti, Catherine Le Gallès, Claire Julian-Reynier and Ségolène Aymé, 'Le diagnostic prénatal 
While PND was becoming rooted in the clinic, practitioners organised collegial practices. At the end of the 1970s, most hospitals in which there were PND practitioners had created multidisciplinary teams that met regularly to discuss possible MTP cases. They had two functions: 1) emotional, they avoided the practitioner having to make a decision on his/her own, making it possible to defer what was often a difficult decision and sharing responsibility by calling upon complementary skills; 2) ethical, these teams constituted a space for reflection upon practices and made it possible to introduce local regulations. The oversight committee at Toulouse hospital is one such example among many. ${ }^{37}$ The interactions developed between obstetricians, paediatric geneticists and foetal pathologists, along with improvements in technical performance, particularly in the field of ultrasound, led to the emergence of a new medical segment: ${ }^{38}$ foetal medicine. A learned society - the Club de Médecine Fotale - and a journal of the same name, were created in the mid-1980s. Training was then organised and an annual Foetal Medicine Congress came into being in the 1990s.

Unlike other countries, such as Germany for example, ${ }^{39}$ PND practices were introduced in France in a slow and quiet fashion. The main driving forces were the government's total delegation to geneticists and biologists and the French health system's funding of PND programmes before abortion legislation had even been passed. The shift from laboratory to clinic took place just as smoothly due to medical eugenics being traditionally present in France. ${ }^{40}$ Most of the pioneering PND geneticists were indeed both researchers and physicians. There was no public debate on the matter. ${ }^{41}$ Public debate did not cover medical abortion, as feminists defended free abortion with support from doctors other than those promoting PND. Disabled persons groups were slow to react and adopted a liberal and nuanced stance. The economic argument that had caused public controversy in countries such as Sweden, ${ }^{42}$ although probably mobilised by the government to decide on how to fund the programmes, remained implicit. In such a context, practitioners and researchers remained perfectly autonomous when it came to regulating their own practices.

\section{The Era of Regulations}

The situation changed in the 1990 s and to an even greater extent in the 2000s. The cognitive and moral context surrounding clinical practice in general was transformed. In France, as in most Western countries, a liberal vision of genetic counselling replaced the previous prevention of disability. ${ }^{43}$ PND would be framed no longer as a means 'to prevent

des anomalies chromosomiques en France et en RFA. Intérêt et limites d'un modèle d'autorégulation professionnelle', in B. Jobert and M. Stephen (eds), Comparaison France-Allemagne des politiques de santé (Paris: Espace Social, 1994), 147-59.

${ }^{37}$ Membrado, op. cit. (note 15).

${ }^{38}$ Rue Bucher and Anselm Strauss 'Profession in Process', American Journal of Sociology, 66, 4 (1961), 325-34.

39 Suzanne Doetz, 'The happiness of the individual is of primary importance: genetic counselling in the GDR', in Petermann et al, op. cit. (note 1), 393-420.

40 Anne Carol, L'eugénisme en France. Les médecins face à la procréation (Paris: Flammarion, 1995).

41 The only controversy that arose was within the world of genetics, embodied in the conservative person of Jérôme Lejeune, who was rapidly marginalised due to his anti-abortion position and his close relationship with the Vatican. Peter Harper, interview with André and Joëlle Boué, 22 April 2005, Genetics and Medicine Historical Network, https://genmedhist.eshg.org/fileadmin/content/website-layout/interviewees-attachments/BoueAJ.docx. pdf; 'Witness Seminar: Histoire du DPN en France', http://anr-dpn.vjf.cnrs.fr/?q.node/62.

42 Björkman and Tunlid, op. cit. (note 19).

${ }^{43}$ It should be noted that the term 'genetic counselling' is rarely used in France. The profession of conseiller en génétique et en médecine predictive (consultant in genetics and predictive medicine) was recognised in 2004, but these consultants rarely attend PND consultations. Generally speaking, it is midwives who provide women with information on the risks involved, or else obstetricians and geneticists, once a risk has been confirmed. 
children with serious diseases from being born, but rather 'to assist pregnant women in making their own choices'. ${ }^{44}$ An ethical split in fœtal diagnosis arise 'during which the providers of the technology assume the responsibility for only the reliability of the technologies while the ethical and existential choices about the selective termination of pregnancies to pregnant women personal choice and autonomy of women and family are in the fore'. 45

The logic of rational choice increasingly dictated both official discourse and medical consultations; decisions on whether or not to opt for prenatal screening and diagnosis were increasingly left to the private sphere and private individuals. ${ }^{46}$

This transformation was particularly reflected in a new determination to regulate and control practices in France. In the wake of the 1994 law on bioethics, policymakers introduced one regulatory text after another to govern practices and to officially certify professional bodies. Regarding the decision to perform a MTP, the law made it obligatory for the woman to seek authorisation from a CPDPN. Each centre comprised a coordinator, obstetricians, sonographers, geneticists and neonatologist-paediatricians, often with other specialists such as surgeons, paediatric cardiologists, foetal pathologists, psychologists, and so on. Every request for an MTP was required to be discussed by a multidisciplinary staff, who gave a consultative opinion; two doctors working in the chosen centre were required to sign the attestation authorising an MTP. CPDPNs were and still are located in public or not-for-profit care centres, with the aim of offering equal access to healthcare. ${ }^{47}$ Centres vary in size, history and organisation. The Agence de la biomédecine (ABM), a state agency essentially made up of doctors, was tasked with monitoring PND equity and homogenising practices throughout the country. ${ }^{48}$ Since the ABM was set up in 2004, CPDPNs have each year provided the Agence with an activity report detailing the number of MTPs performed per type of foetal pathology and the term of pregnancy at which they took place. The Agence is tasked with gathering, analysing and disseminating the annual reports issued by the centres. It has made recommendations that regulate the practice and obligations of doctors and that place women's decision-making autonomy at the heart of the prenatal consultation.

Over a period of ten years, a whole range of regulatory texts were passed to ensure that practices remained equitable and homogeneous, removing medical decision-making (particularly that of pregnancy termination) from the doctor-patient relationship and placing it under peer control, within the framework of collegial practice, supervised by a government agency and regulated by legislative texts. After several decades of total delegation to doctors, the State would appear to be wanting to take back control of PND practices. One might wonder about the effectiveness of this new regulatory framework, about the manner in which practitioners have appropriated it and about how it has affected PND practices at population-level.

\footnotetext{
${ }^{44}$ Schwennesen et al, op. cit. (note 16). Clarke, op. cit. (note 16).

45 Björkman and Tunlid, op. cit. (note 19), 342.

46 Paul, op. cit. (note 5).

${ }^{47}$ See the witness seminar organised by our research team in 2012: http://anr-dpn.vjf.cnrs.fr/?q.node/62.

48 The Agence de la biomédecine also plays a role in organ donation and transplant, preimplantation diagnosis and postnatal genetics.
} 


\section{Prenatal Diagnosis Practices in CPDPNs: A Comparative Analysis}

In this second part of the article, I draw on two types of data to shed light, comparatively, on the transformations of practices induced by the regulatory framework that had been imposed on practitioners. The first section compares the activity records of each centre, in particular the number of MTP certificates signed each year according to the type of foetal indications. This analysis makes it possible to objectify differences in attitudes between centres and to question therefore the alleged homogeneity of practices that dominated professional discourse. The second section presents a comparative ethnographic analysis of two centres. Indeed, it is only through the direct observation of these practices, located in singular local contexts, that the researcher can identify processes and mechanisms that accounted for the differences observed quantitatively. As a result, this section covers three themes that emerged inductively from the data. The first theme concerns the organisation of the teams' work, while the other themes derive from deliberations and decision-making processes, namely the way MTPs were discussed and uncertainty and disability tolerance.

\section{CPDPNs Activity: Apparent Homogeneity}

Today, official discourse typically declares that the objective of PND practice regulation has been met. Practitioners and experts unanimously point out the considerable homogeneity in the indications that are the object of MTP authorisations. ${ }^{49}$ The argument is based on the analysis of centres' refusals to accept couples' requests for an MTP. Such refusals are in fact rare (less than 2 per cent of requests), which, as far as the ABM is concerned, is evidence of a high level of consensus between couples and professionals with regard to what constitute 'acceptable' indications:

We find few differences between the opinions of CPDPNs and those of couples, as in 2007 CPDPNs refused only 112 attestations for 6,645 issued (1.7\%) (ABM internal note, November 2009).

Furthermore, these refusals related to a limited number of indications that were identical in all centres (cleft lip, unilateral and partial agenesis of a limb, Klinefelter syndrome, and so on), which professionals in this field believe to illustrate the homogeneity of their practices:

The experiences of French multidisciplinary centres that submit annual reports on their activities to the Agence de la Biomédecine show that overall, throughout France, there is a high level of consensus on pathologies that are accepted without discussion (for MTPs). But there are also the same hesitations and ambiguities concerning pathologies that are seen as controversial and contestable and that are more or less the same for all teams (Fernand Daffos, foetal medicine specialist). ${ }^{50}$

Yet is the homogeneity of indications for refusing MTP requests sufficient to assert the homogeneity of practices relating to MTP decisions? Upstream of a refusal, it is important to look at the space allowed for making a request. Are the conditions created for the expression of the possibility of having a MTP the same for all of the various CPDPNs, even when women come from different cultural backgrounds? Or will practitioners decide whether or not to open the door to discussions depending on their perception of the pathology, its consequences and their incorporate assumptions about women ${ }^{51}$ The following extract from a consultation with a migrant couple, following a foetal

\footnotetext{
${ }^{49}$ In France there are approximately 800,000 births per year and slightly less than 1 per cent of MTPs performed, one-third of which take place after twenty-two weeks of amenorrhea. This number has remained relatively stable since 2009 (annual ABM reports).

${ }^{50} \mathrm{http}: / /$ www.diagnostic-prenatal.fr/indicimg.htm.

${ }^{51}$ Rapp, op. cit. (note 14).
} 
karyotyping, shows how the way in which the detected foetal pathology is presented to the couple cuts short any possibility of requesting a MTP:

Geneticist: we were worried that your baby had Down syndrome (...). He doesn't have that at all, but he does have a small anomaly that is far less serious. We weren't looking for it, but we found it. So I'm going to give you some information about it (...). No malformation showed up on the ultrasound scan. Everything is fine. But we discovered something else that is a little unusual. Your baby has an extra chromosome. This causes problems, but they are not very serious. (...) It's called Klinefelter syndrome. He's a perfectly normal boy with normal genital organs, and as he grows everything will remain perfectly normal. A problem which may occur is that around the age of ten to twelve ... (explanation about puberty). We'll monitor him and he'll become a man. He will be a man with a normal sex life, he will have sperm, but he won't be able to have children normally (...). Nowadays we can help (people with this condition) have children using laboratory techniques. Twenty years from now it will be even easier. So your son, he has problems, we're not going to pretend everything is fine. He'll need to be monitored and he'll have problems having children. We know many people in this situation. It's not particularly serious. Have I made the situation clear?

Once the couple had left, the geneticist explained that there were 'certain things' she had not said, particularly the fact that statistically speaking Klinefelter boys have an IQ ten points lower than that of their siblings. She added that in the CPDPN where she works, they no longer offer MTPs for Klinefelter syndrome, though they do sometimes accept requests, particularly where a couple has been given negative information by another practitioner. $^{52}$ The positive way in which the pathology is described is one of the elements likely to inhibit a request for an MTP. We might think that the geneticist is acting in a collective way. In trying to prevent any such request which would be embarrassing for the medical team, she is helping to strengthen the norms established in the centre. Whatever the case may be, while we might hypothesise that there are differences between CPDPNs regarding the space allowed to women to make MTP requests, their annual activity report does not allow us to verify this. These reports nevertheless provide interesting information.

A comparative analysis of CPDPN activity is difficult to achieve as there is no common denominator that allows a comparison of the centres in terms of the number and indications of the MTPs that they annually perform. The volume of activity varies considerably from one centre to another and we cannot know the zones that each centre covers, as couples are free to contact the CPDPN of their choice. As I will come back to later, the number of case files discussed during multidisciplinary meetings also varies in accordance with different internal traditions.

This said, the way in which the data are gathered makes it possible to get around this difficulty. Attestations authorising MTPs are recorded by type of original indication: chromosomal, genetic and malformative. The malformative indication category excludes those whose origin is known to be caused by a chromosome or gene. Table 1 shows the spread of indications for which MTP attestations were signed in 2009. ${ }^{53}$ We can see that chromosomal and malformative anomalies account for 86 per cent of all attestations, yet each category has its own specificities. Chromosomal anomalies constitute the main core of routinised PND activity: they are stable within the population, homogeneous throughout the country, have been identifiable for a long time and in the vast majority of cases are the object of MTP authorisation. On the other hand, as I have observed, malformation is a blurred category, associated with suspicious images that are sometimes difficult to interpret

\footnotetext{
${ }^{52}$ Klinnefelter syndrome is one of the conditions now deemed less severe than was the case in the past.

53 The Agence de la biomédecine gave me access to these data, which are not in the public domain. For reasons of comparability and robustness, I only retained for analysis the prenatal diagnosis centres (CPDPN) that issued one hundred or more medical termination certificates in 2009.
} 
and, even when there is no doubt, such as with an agenesis of the corpus callosum, ${ }^{54}$ their functional consequences remain uncertain. We can assume that while there are indeed disparities between practices, they relate to uncertain situations, those located in the 'grey area' (to use the practitioners' own term). For all of these reasons I felt it was reasonable to consider the number of diagnosed chromosomal anomalies as a common denominator that enabled comparison of the activity of the different centres.

Table 1 shows that, overall, there are slightly more MTPs for the malformation indication than for chromosomal anomaly: 46 per cent compared to 40 per cent; in other words, a ratio of 1.15. Yet if we compare centre indications, we find ratios that vary up to 100 per cent, ${ }^{55}$ which suggests that PND practices are far from homogeneous. This suggests that differences in attitude between the centres in relation to the 'malformation' category might therefore reveal different practices regarding the way in which MTPs are approached and, more specifically, the space allowed to women to make a request. Different logics of action appear to continue despite the national regulatory framework designed to ensure homogeneity. To understand the reasons behind these different logics of action, the next section turns to the ethnographic observations of these practices through a case study of two centres.

\section{Playing with the Regulatory Framework: Between Preservation and Commitment}

My observations were made between 2010 and 2012 in a Paris centre and in a provincial centre. In each centre, I attended a large number of consultations with obstetricians, geneticists, sonographers, neonatologists and midwives, as well as the weekly meetings of the multidisciplinary teams. I also carried out interviews and was present during more informal moments of the practitioners' work. All of the ethnographic material was transcribed and analysed using Grounded Theory and NVivo software. ${ }^{56}$ Far from focusing solely on professional attitudes towards MTPs, the comparative analysis looked more broadly at how each centre organised its practices so as to conform to the new regulatory requirements.

The two CPDPNs present certain similarities. Both were located in university hospitals, which places them at the cutting edge of new technologies and research in PND. They both had a high volume of activity, with over 200 MTP attestations issued in 2009. Both centres had experience with collegial work well before the law on bioethics came into effect. ${ }^{57}$ At the time of the fieldwork, the multidisciplinary team met every week to discuss a certain number of cases of suspected or diagnosed foetal pathologies, to make a decision concerning additional tests to be done or to envisage the possibility of an MTP. Both teams were coordinated by men who were heads of department within the hospital hierarchy - an obstetrician for the Paris centre and a geneticist for the provincial centre. ${ }^{58}$

\footnotetext{
54 The corpus callosum is the part of the brain that links the two cerebral hemispheres.

55 With centres $\mathrm{T}$ and $\mathrm{V}$ at the extremes.

56 Juliet Corbin and Anselm Strauss, Basics of Qualitative Research: Techniques and Procedures for Developing Grounded Theory (London: Sage Publications, 1998).

57 Teams were then limited to just a few hospital practitioners, with different specialisations, required to work together. Several informants mention the confrontational atmosphere of the initial debates that took place in the early 1980s, due to the specialists' diverging views on the consequences of the pathologies and on the resulting quality of life. Membrado, op. cit. (note 15).

58 This information is worthy of mention, even though the data do not allow us to identify their effects. Several studies have demonstrated the effect of gender and of practitioner specialisation on the decision-making process. Among others: Louise Bouchard and Marc Renaud, 'Female and Men Physicians' Attitudes Towards Prenatal Diagnosis', Social Science \& Medicine, 44, 3 (1997), 381-92. Arthur Robinson, Bruce G. Bender, Mary G.
} 


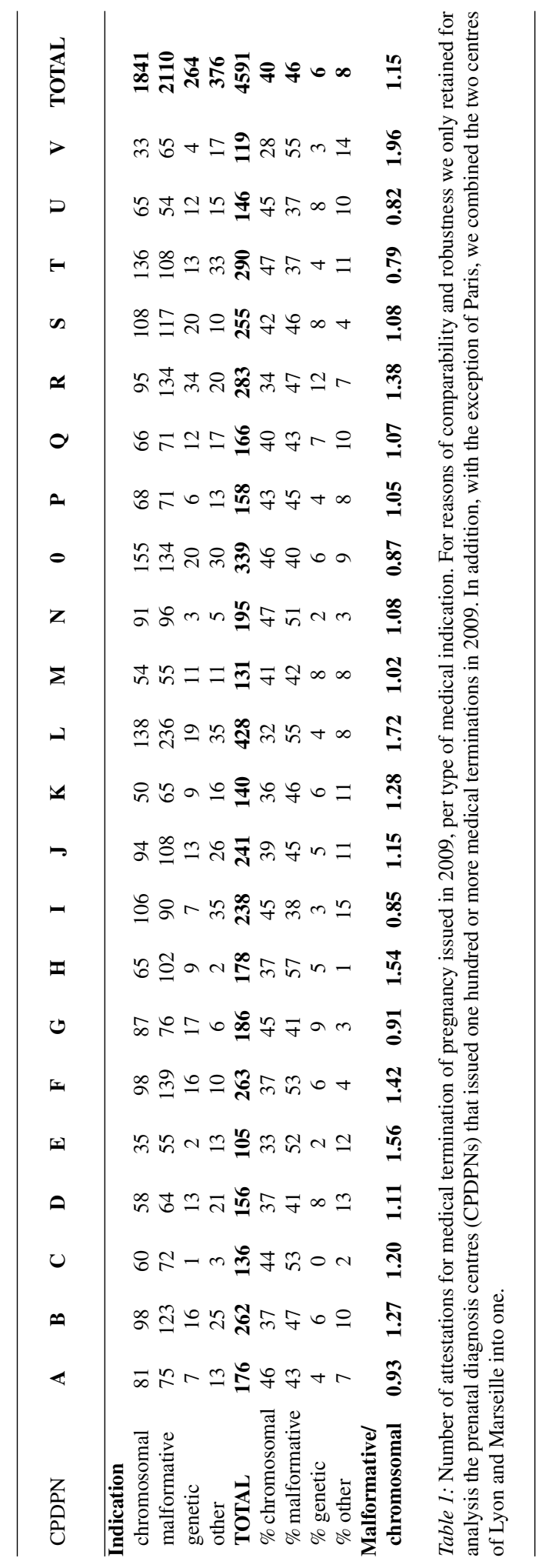


Their populations differed, however, with the Paris centre dealing with a larger number of women from poorer backgrounds, most of whom were immigrants. This is an important point. As with Rayna Rapp in New York, ${ }^{59}$ I observed that practitioners' attitudes differ in line with their presuppositions concerning women's language skills, level of education, religious beliefs and understanding of the law on abortion. The Paris centre issued more authorisations for malformative pathologies and refused fewer MTPs than the provincial centre. ${ }^{60}$

My comparative analysis reveals differences between the centres that illustrate the attitudes of the practitioners towards the recommendations and regulations that they were required to follow, and sheds light on the heterogeneity of practices. The differences relate to the way the teams organised their everyday work, how they discussed the cases put before them during staff meetings and approached the MTP issue.

\section{Organisation of the Teams' Work}

In the Paris centre, conformity to the regulatory framework was achieved in such a way as to modify as little as possible the centre's historical practices by exercising complete control of the format of meetings and by containing discussions in space and time. The desire for efficiency predominated, aided by strict hierarchical relations. Staff activity was centralised and formalised. Two midwives were dedicated full-time to preparing the multidisciplinary meetings. They collected the files, asked for any missing information, prepared a slide show of all the cases to be presented, in accordance with a standard model, and sent all of this by email to all participants prior to the meeting.

While regulations govern the composition of the teams and have increased the number of participants, including participants from outside the hospital, staff meetings were organised in such a way as to maintain a certain level of intimacy. The room in which they took place was isolated. The participants - practitioners from the multidisciplinary team, along with others from maternity units associated with the CPDPN if one of their patients is to be discussed - gathered in a small amphitheatre which may only be accessed by personnel with a badge. At the bottom of the amphitheatre, in the middle of the platform, sat the coordinator, surrounded by the department secretary, who took notes, one of the CPDPN's two midwives, who had stacked in front of her the pile of files to be discussed, and finally the clinical assistant, who presented all of the cases out loud. On the opposite side of the boss was the consultant sonographer in front of an overhead projector and, next to her, the MRI specialist. They each commented on all of the imaging that was projected onto the large screen behind the platform. Aside from a few key personnel who felt that they could legitimately interject with spontaneous comments, the majority of participants in the room only spoke when the coordinator invited them to do so. Prior to each team meeting, the files were organised by medical specialty and presented in order of specialty, thus allowing the relevant specialists to leave the room and others to come in later. Once

Linder, 'Decisions Following the Intrauterine Diagnosis of Sex Chromosome Aneuploidy', American Journal of Medical Genetics, 34, 4 (1989), 552-4. Theresa M. Marteau, Irma Nippert, Sue Hall, et al, 'Outcomes of Pregnancies Diagnosed with Klinefelter Syndrome: the Possible Influence of Health Professionals', Prenatal Diagnosis, 22 (2002), 562-6. These studies were nevertheless conducted some time ago, and we can assume that a more collegial practice has helped to reduce such effects.

${ }^{59}$ Rapp, op. cit. (note 14).

${ }^{60}$ In 2008, the ratio of malformative pathologies to those of chromosomal origin was 1.41 in the Paris centre, compared to 0.74 in the provincial centre. A similar, albeit smaller, difference was found in 2009 ( 1.08 vs 0.85$)$. Furthermore, between 2007 and 2009 the Paris centre refused just one case of MTP request, as opposed to seven in the provincial centre. 
again for reasons of efficiency, before the weekly meeting there was a 'pre-staff meeting' during which the case files were selected so that only those that were subject to a regulatory obligation, sometimes interpreted relatively loosely, were presented at the weekly meeting.

The provincial centre had seized upon the regulatory obligation as an opportunity to create cohesion in practices that were dispersed not only between the public and private sectors, but also geographically. In contrast to the Paris centre, many of the team members divided their time between sessions at the hospital and freelance activity. Multidisciplinary meetings thus included specialists from both the public and private sectors. The stronger heterogeneity of the participants went some way towards explaining why, regulatory mission aside, the staff meetings had a combined function of socialisation and training student midwives (in particular). This is also why the discussions were not limited to cases subject to a legal obligation, but could also include any other situation that a practitioner might wish to discuss with his/her peers.

Another important particularity of the provincial centre was the geographical dispersion of its associated maternity units, some of which were as far as $150 \mathrm{~km}$ away. This problem was solved through a videoconferencing system that may be simultaneously used by up to five peripheral entities, in which one, two or three practitioners could join for all or part of a staff meeting. Speaking time was thus divided between the centre and the peripheral entities. The result was that unlike the 'between ourselves' situation that prevailed in the Paris centre, the contours of the multidisciplinary meetings held by the provincial centre were variable and uncertain.

The way staff meetings were organised was friendlier and less formal than in the Paris centre. They took place in a room that was barely large enough to hold all of the participants. The latter came together around a large table (for the first to arrive) and in a second circle for the remainder. The coordinator always sat in the same position with, on his left, the secretary who notified the decisions and, on his right, a geneticist who replaced him should the need arise. The number and nature of the case files to be presented were not known in advance, with each practitioner bringing his/her file(s) on the day of the meeting; some of them showed slides, but this was not systematic. There was no particular order of presentation. Practitioners entered and left the room in a haphazard fashion, in accordance with their availability, so it was not unusual for a given patient's case to be brought up at different moments during the meeting, by specialists who were not all present at the same time.

So, while the regulatory framework introduced in the 1990s and 2000s affected the number of members and composition of the teams, as well as the nature of the case to be presented - in particular by requiring that all indications that might give rise to an MTP be the object of collective discussion ${ }^{61}$ - these formal changes had little impact on the work organisation of the teams created beforehand, with full autonomy and wish to maintain their traditions. Yet this practical configuration of staff meetings was not without consequence for the form and content of the discussions that took place therein.

\section{Deliberations and the Decision-making Process}

The substance of the discussions that took place during the weekly multidisciplinary meetings also reveals marked differences in the way in which the practitioners at the two

\footnotetext{
${ }^{61}$ At the beginning of my period of observation, the Down syndrome cases for which couples had requested an MTP were not presented at the staff meetings in Paris as authorisation was taken for granted. The intervention of an $\mathrm{ABM}$ inspector led to this assumption being corrected.
} 
centres adjusted their practices to comply with the regulatory framework. I will focus on two aspects that emerge from the comparative analysis: ways of talking about MTPs and perception of the risk of anomaly, both of which illustrate how the actors accommodate the rules and thus sustain the heterogeneity of their practices.

\section{MTPs: How Were They Discussed?}

In the Paris centre, the practitioners openly and very directly discussed the possibility of a MTP. This attitude was based on a strongly held historical position, deemed by the centre's practitioners to be a specificity of their practices, even though it was in tension with the principle of non-directiveness recommended in the guidelines: ${ }^{62}$

Coordinator: When we meet the parents, and it's a serious case, (...) we suggest, we tell them it's serious and that they can terminate the pregnancy. Under normal circumstances it is up to them to ask, but in this case we suggest it. We follow the line laid down by my predecessor, who I knew well and with whom I had a good relationship. We tell them 'it's your decision'. If they wish to keep the baby, we tell them we will look after it and we advise them. But we make the suggestion. I have colleagues who say that's not good, that it should be left to the parents to ask. We're the only ones who do that. It's specific to us.

This tradition was established by the previous head of department, who had introduced collegial meetings in the early 1980s and who 'believed that it was not down to the parents to bear the guilt of killing their child', according to the current department's supervisor. This point of view dominated the field of perinatal care, particularly regarding decisions to cease care for very premature infants. ${ }^{63}$

It governed the Paris centre's multidisciplinary discussions, adding an additional degree of freedom to the decision-making process. Whenever a serious pathology was diagnosed, or when a risk was deemed to be serious, the issue was whether or not a MTP should be suggested. A sort of implicit three-point scale had been established: there were some indications for which the practitioners suggested to the woman/couple that a MTP be performed; other indications for which they accepted if the woman made the request; and still others for which they refused.

In the following extract, consensus was sought to qualify the case of a foetus at thirty weeks of amenorrhea that presented several malformations that were not life-threatening and did not affect the brain. A chromosomal anomaly (inversion of the third chromosome) was discovered. Should a MTP be suggested, or not?

Coordinator: What do we suggest to parents with a Fallot, an intrauterine growth retardation, a single kidney?

Geneticist 1: I wouldn't be shocked if we suggested termination.

Coordinator: If it is a de novo (there is no other case of the chromosomal anomaly in the family), then we must suggest a termination. Is the risk high enough to suggest a MTP?

Geneticist 2: There are VACTERLs [acronym for this type of syndrome] who are fine.

Coordinator: So we need to complete the diagnosis.

Geneticist 2: Give us a week.

Coordinator: If the parents want a MTP, we'll accept and we'll do the tests after.

In the provincial centre, the question of pregnancy termination was far less frequently discussed during team meetings. They made decisions on the gravity of the pathology, as required by the recommendations, and when there was no doubt that the foetus was

62 Williams et al, op. cit. (note 15); Clarke, op. cit. (note 16).

63 Anne Paillet, Sauver la vie, donner la mort (Paris: La dispute, 2007). 
suffering from a serious pathology, this was notified in the report using standard wording that reflected the terms of the law authorising MTPs. In such situations, if the couple so requested, termination was accepted.

When the possibility of an abortion was expressed, it was done so with some restraint, usually in a euphemistic form which was in contrast with the head-on approach of the Paris centre. The practitioners used roundabout phrasing such as: 'What are the parents' thoughts at this time?' or 'What is the woman tending towards?' Once it had been accepted that the pathology fell within the parameters defined by the law, the practitioners might consider the wishes of the woman or couple:

Coordinator: This is such a worrying intrauterine growth retardation that we must ask whether it is a situation with a high risk of a seriously debilitating anomaly that justifies a MTP, with the additional anomaly of the genital organs.

Sonographer: The (growth) curve is far below the third percentile. The cranial perimeter is more or less protected. It is difficult to estimate foetal weight under these conditions.

Coordinator: Is she asking for a termination?

Sonographer: She's worried, she hasn't asked, but she is aware that the question may arise. We need to give her the information.

One of the meetings I observed was especially useful in clarifying the attitudes adopted in the provincial centre, due to the presence of a new head of department. After discussing the case, and faced with a severe pathology, the coordinator announced the verdict, which was noted by the secretary:

Coordinator: Affection with a high risk of being seriously debilitating and incurable. Indication of karyotyping in the etiological report.

New participant: At what point do you talk about termination of pregnancy? Are you envisaging a MTP?

Coordinator: We put 'high-risk affection' in the report. The obstetrician has the arguments.

The reply was cryptic and demonstrates the coordinator's wish to go no further than his responsibility to state the seriousness of the anomaly and its incurability. In the intimacy of the doctor-patient encounter, the obstetrician was free to act as he/she saw fit. My observations nevertheless show that at the provincial centre the practitioners tended to adopt a wait-and-see attitude, to observe the couple's thought process, and tried to respect the principle of non-directiveness. Yet the way staff meetings were configured, not allowing people to know who was present when they were speaking, tended to cause discussions to be 'smoothed over', something that was very different from the direct and sometimes even crude exchanges observed in the intimacy of the Paris centre.

\section{Uncertainty and Disability Tolerance}

French PND practitioners had made the most of the wiggle room available in their interpretation of the law authorising MTPs, to define the boundaries of the new professional specialism of foetal medicine. ${ }^{64}$ Legislators, in turn, had left them free to decide upon the 'strong probability', 'particular gravity' and 'incurability' of the foetal

\footnotetext{
${ }^{64}$ As a new 'medical segment', foetal medicine groups several specialisations together (obstetrics, genetics, radiology, foetopathology, etc.). It involves specific training (university diploma in foetal medicine), has its own society (the Foetal Medicine Club, created in the mid-1980s) which organises regular conferences, and its own journal (The Foetal Medicine Journal). Véronique Mirlesse, 'Diagnostic prenatal et medecine fœtale. Du cadre des pratiques a l'anticipation du handicap. Comparaison France-Bresil' (unpublished $\mathrm{PhD}$ thesis: Université Paris-Sud, 2014). Refusing to be mere implementers of the abortion law, its practitioners offer their own definition of PND: 'Prenatal diagnosis is a tool which must make it possible to foresee a treatment at birth, to improve
} 
pathologies they encountered. While these criteria were at the heart of the deliberations, generally speaking doctors agreed on the acceptability of certain risks. 'Curability' in particular was often assessed in terms of the surgical techniques available. If early surgery could repair an anomaly, it must be attempted. This was the case for isolated diaphragmatic hernias, which could be operated on in the days following birth with, according to practitioners I observed, a 50 per cent chance of survival. Unless there were complications, termination of pregnancy was not envisaged in such cases. Taking this risk helped to improve surgical techniques. This was particularly the case for the transposition of the great heart vessels. Nowadays 95 per cent of new-born babies survive the operation. ${ }^{65}$ Twenty years ago, 20 per cent died and 20 per cent suffered from complications due to a lack of oxygen. ${ }^{66}$ If they were not too major, morphological malformations (such as an agenesis of the hand, for example) were deemed acceptable by practitioners. There was of course disability, but children (in their own opinion) successfully overcame this. ${ }^{67}$ On the other hand, failure to identify a 'polymalformative syndrome', generally associated with mental retardation, remain a common fear, illustrating a form of historical continuity between PND practices and eugenics. ${ }^{68}$ While medical imaging was able to detect an increasing number of anomalies, its ever-improving performances also generated more uncertainty. ${ }^{69}$ As I frequently observed during the ultrasound consultations and staff meeting discussions, every suspicious image led to fear that there was a malformative pathology. Discussing whether it was an artefact, a 'variant of the normal', an irrelevant particularity or a sign that fit the description of a known syndrome, practitioners tried to bridge the gap between pre-screening and post-screening knowledge. ${ }^{70}$ The latter hypothesis was generally prioritised and practitioners then strove to find other related signs that would allow them to reject or confirm.

Even when a diagnosis had been made, the consequences in terms of disability sometimes remained very uncertain, because for some anomalies the spectrum of clinical

the arrival of a new-born baby in difficulty and above all to treat and cure in utero patients'. R. Shojai, L. Boubli, C. d'Ercole, 'Prognosis Work-up in Prenatal Medicine: The Example of Down's Syndrome', Gynécologie Obstétrique \& Fertilité, 33 (2005), 514-9: 518. It reverses the definition in the French public health code and of the law that defines PND as 'all medical practices the purpose of which is to detect, in utero, in the embryo or foetus, an affection of particular gravity' (Code de la santé publique - Article L2131-1).

65 D. Bonnet, A. Coltri, G. Butera, L. Fermont, J. Le Bidois, Y. Aggoun, P. Acar, E. Villain, J. Kachaner and D. Sidi, 'Prenatal Diagnosis of Transposition of Great Vessels Reduces Neonatal Morbidity and Mortality', Archives des Maladies du Coeur et des Vaisseaux, 92, 5 (1999), 637-40.

${ }^{66}$ In the same vein, Deborah Blizzard shows how the ban on abortion in a Catholic clinic encouraged practitioners to attempt in utero surgery: Deborah Blizzard, Looking Within: A Sociocultural Examination of Fetoscopy (Cambridge, MA: MIT Press, 2007).

${ }^{67}$ On this precise point, my observations reveal the influence of a paediatrician, specialising in limb agenesis who became heavily involved in prenatal diagnosis and who had talked a great deal about his healthcare practices and the quality of the children's lives. Didier Pilliard, Gérard Taussig, Bernadette Boulot and Marie-Laure Devanz, 'Les cas limites et leur prise en charge: réflexions sur les demandes d'interruptions de grossesse pour anomalie des membres', in Véronique Mirlesse (ed.) Interruption de grossesse pour pathologie fotale (Paris: Flammarion Médecine-Sciences, 2002).

${ }^{68}$ Paul op. cit. (note 5) clearly shows that eugenics emphasised mentality and behaviour and that mentality remained a primary concern after the post war period. In the Paris centre, a risk of mental retardation, assessed at 15 per cent but incurable, might be considered to be an indication that justified pregnancy termination.

${ }^{69}$ Bénédicte Champenois-Rousseau, 'Éthique et moralité ordinaire dans la pratique du diagnostic prénatal' (unpublished PhD thesis: École Nationale Supérieure des Mines de Paris, 2003), https://pastel.archives-ouvert es.fr/tel-00005674/document.

${ }^{70}$ Stefan Timmermans and Mara Buchbinder, 'Expanded New-born Screening: Articulating the Ontology of Diseases with Bridging Work in the Clinic', Sociology of Health \& Illness, 34 (2012), 208-20. 
manifestations could be very broad. ${ }^{71}$ A typical case for the study of an 'acceptable' and ultimately frequent risk was the agenesis of the corpus callosum, the part of the brain that links the two cerebral hemispheres. ${ }^{72}$ Whether partial or total, in 50 per cent of cases it is linked to other signs and belongs to a potentially severe clinical table. In the remaining 50 per cent of cases it is isolated and may have no consequences. ${ }^{73}$ Diagnosis was difficult; it was achieved through imaging from eighteen weeks of amenorrhea, but could only be definitively established by an MRI at thirty-two weeks of amenorrhea. Practices had for a long time been based on studies showing that a significant proportion of children without corpus callosum had moderate to severe mental retardation. Yet a most recent study conducted by Marie-Laure Moutard, a French paediatric neurologist who monitored a cohort of children with an agenesis of the corpus callosum, shows that in one-fifth to one-quarter of cases the children presented a moderate to severe intellectual deficit and that in three-quarters of cases their IQ was normal or very slightly below average. ${ }^{74}$ The discovery of an agenesis of the corpus callosum plunged those involved into considerable uncertainty, which was a source of anxiety for couples who might then be tempted to ask for a MTP without waiting for the definitive diagnosis. In this case, the indication was recorded in the 'malformation' category. In both centres, I was able to observe several discussions on the conduct to follow when facing such a situation.

Once again, the two extracts from these observations illustrate different ways of managing uncertainty and apprehending the risk relating to the consequences of the anomaly. In the Paris centre, a partial agenesis of the corpus callosum was discovered at twenty-four weeks of amenorrhea:

Coordinator: $\mathrm{X}$ [sonographer] is wondering if there's an agenesis of the posterior corpus callosum. We must nevertheless offer a karyotype and virus test (it is a question of eliminating an anomaly linked to a syndrome).

Geneticist: I don't know, but we felt that as a prognosis a partial agenesis was no better than a complete agenesis! We need the neurologist's opinion (absent that day). We are pretty much convinced that he'll suggest a termination. That's what he's proposed more than once in this type of case, so we need him to give his opinion, to meet her before we reach twenty-two weeks.

The exchange shows that practitioners did not wish to take the risk of mental retardation, whatever the extent might be. In Paris, the risk of mental retardation frequently cropped up in discussions as a decisive argument for the action to be taken: to 'suggest' a MTP or to wait for the woman to request one. The provincial centre, in comparison, used more neutral terms:

\footnotetext{
${ }^{71}$ Known syndromes have been described on the basis of their clinical manifestations, taking their most severe forms. Studies of cohorts, costly and sometimes difficult to carry out due to the rarity of certain pathologies, are few in number and often outdated. While molecular genetics has made it possible to identify the less severe or asymptomatic forms of certain syndromes, practitioners' representations often remain marked by the initial descriptions. Generally speaking, when they do exist, recent studies that deal with congenital anomalies (such as isolated agenesis of the corpus callosum and Klinefelter syndrome, for example) or with suspicious ultrasound signs (such as cervical cystic hygroma) report less severe consequences than those found in the past. However, recent studies report associations between certain chromosomal anomalies, such as Klinefelter syndrome, and forms of mental disorders: M. Cederlöf, A. Ohlsson Gotby, H. Larsson, E. Serlachius, M. Boman, N. Långström, M Landén and P. Lichtenstein, 'Klinefelter Syndrome and Risk of Psychosis, Autism and ADHD', Journal of Psychiatric Research, 48, 1 (2014), 128-30.

72 Prevalence is estimated at between one person in 300 and one person in 400: https://www.orpha.net/data/ patho/Pub/fr/AgenesieIsoleeCorpsCalleux-FRfrPub447.pdf.

${ }^{73}$ Paul K. Lynn, 'Developmental Malformation of the Corpus Callosum: A Review of Typical Callosal Development and Examples of Developmental Disorders with Callosal Involvement', Journal of Neurodevelopmental Disorders, 3 (2011), 3-27.

${ }^{74}$ Marie-Laure Moutard et al, 'Agenesis of Corpus Callosum: Prenatal Diagnosis and Prognosis', Child's Nervous System, 19 (2003), 471-6.
} 
Coordinator: It's an isolated complete agenesis of the corpus callosum. We need to provide full information. Many of these children are fine. If the parents ask for a medical termination, we accept. That's the attitude of Marie-Laure Moutard who monitors these children over the long term. The results are reassuring but don't give us enough information to be able to refuse (an MTP) for these indications.

So if the woman asked for it, her wish would be granted. Returning to her case a little later, he added: 'In 60 per cent of cases we don't know what to do with a corpus callosum that is short and thick. We perform MTPs, which are associated with uncertainty. I suggest a midway recommendation: a diagnostic ultrasound.'

The provincial centre's coordinator based himself on the existing state of medical and scientific knowledge to assess the uncertainty. According to established tradition, he transmitted this information to young trainee practitioners. He argued for a careful wait-and-see attitude, but would respect the woman's autonomy, following the recommendations on good practice.

\section{Discussion}

My observations in the two CPDPNs show that despite the government's determination to control practices, French PND practitioners at the centres conserved a level of relative autonomy. The Paris centre did its best to limit the impact of the new regulations on its practices. Its firm control of its PND-related activities allowed it to restrain the time spent, and the fact that meetings took place behind closed doors allowed people to speak more freely during discussions. Without taking too much risk, the practitioners continued to adhere to their locally specific culture by suggesting an abortion when a foetal pathology was deemed to be severe, even if this might appear debatable under the new standards of non-directiveness. Conversely, the provincial centre was engaged in the reform movement and clearly demonstrated its adherence to the new regulatory framework; using it to encourage and strengthen the links between professionals across divides of status and geography. On the other hand, the fact that meetings were more accessible meant that care must have been taken during discussions and probably limited their scope.

These differences shed light on the attitudes towards MTP authorisations observed at the macrosocial level. The directive attitude taken in the Paris centre (considered a hallmark), which was to explicitly propose an MTP, demonstrates their resistance to the movement - clearly described by historians of human genetics ${ }^{75}$ - that involved transferring responsibility for decisions relating to reproduction to women and families, while respecting their autonomy. This does not mean that practitioners at the Paris centre explicitly took collective responsibility for the prevention of disability, as was the case in the USA in the $1950 \mathrm{~s} .{ }^{76}$ Here the motive was individual. Some were to see this as the persistence of a form of paternalism designed to unburden women from the guilt of having to decide on the death of the child they were carrying. In any event, this attitude necessarily worked in favour of an MTP being performed. The mechanism - whether this avoided any inhibition that couples may have had about raising the issue themselves, or whether the latter perceived this, from a normative standpoint, as being the correct thing to do - nevertheless remains unclear.

The attitude at the provincial centre, on the other hand, was to provide couples with detailed information on the situation without ever bringing their subjectivity into play, and then to wait for the couples to make their request before discussing with them the

75 Petermann et al, op. cit. (note 1), 570; Paul, op. cit. (note 5); Löwy, op. cit. (note 12).

${ }^{76}$ Paul, op. cit. (note 5). 
possibility of terminating the pregnancy. Here, responsibility for decision-making falls to the women and couples. Such an attitude tends to reduce the number of MTPs performed, as a couple may have envisaged such a possibility without daring to put it into words.

Moreover, my ethnographic observations show a persistent aversion on the part of practitioners regarding the risk of mental deficiency. This is embedded in a historical continuity with eugenics, the ideas and practices of which related more to intelligence than to physical health. ${ }^{77}$ Although it varies in extent from one centre to another, the fear of 'missing' a malformation that might be the cause of a mental deficiency continues to have a strong impact on how practices are oriented. ${ }^{78}$

This trend could be reinforced by rapid developments in comparative genomic techniques such as CGH Array (Comparative Genomic Hybridisation). These techniques are more efficient than karyotyping, since they allow the automated detection of chromosomal micro-deletions and micro-duplications potentially responsible for learning disability and dysmorphic features. ${ }^{79}$ First used in genetic counselling, following an in utero death or MTP, this technique, by obtaining faster and faster results, represented a new resource for prenatal diagnosis. This tool was beginning to be used, in the Parisian centre where I carried out my fieldwork, for cases of foetal malformations identified through ultrasound and of unknown origin.

As we have seen, French regulation of practices, to which practitioners had themselves made a considerable contribution, leaves sufficient latitude for each centre to be able to forge its own identity, in a collegial manner. This latitude could be seen first and foremost in their assessments of the 'strong probability', 'particular gravity' or 'incurability' of the foetal pathologies encountered. The decision on what constituted an acceptable risk varied from one centre to the other. The official discourses that put forward the homogeneous nature of practices in France in fact hide a certain known and accepted latitude for decision-making in the centres relative to situations that might be deemed less severe or surgically 'reparable'. The latitude shown by the practitioners could also be seen in the way they 'played' with the standards and regulations. Each centre was trying to maintain autonomy for the aspects that suited its traditions and values, thus building its own unique identity. In the professional arena, certain centres had forged a reputation of permissiveness; their attitude demonstrated empathy and benevolence towards couples, underlying the suffering that families and children endured when coping with a disability in a normative society. Others would seem to have positioned themselves more as guardians against excessive practices; defending the value of life, they were challenging the boundaries of normality. These values, which used to cause conflict between individuals or specialisations, ${ }^{80}$ would seem to have migrated towards collective bodies: the CPDPNs.

\footnotetext{
${ }^{77}$ Paul, op. cit. (note 5), 122.

78 This fear can also be seen in healthcare policies at national level. Whereas in the UK the NHS recommends non-invasive prenatal testing (NIPT) as a second-stage screening only for women with a risk of 1:150 or higher, France's Haute Autorité de Santé places the cursor at a risk level greater than or equal to 1:1000: https://www.has-sante.fr/portail/upload/docs/application/pdf/2017-05/dir42/synthese_et_recommandatio ns__place_des_tests_adn_libre_circulant_dans_le_sang_maternel_dans_le_depistage_de_la_trisomie_21_f.pdf.

${ }^{79}$ C. Shaw-Smith, R. Redon, L. Rickman, M. Rio, L. Willatt, H. Fiegler, H. Firth, D. Sanlaville, R. Winter, L. Colleaux, M. Bobrow and N.P. Carter, 'Microarray Based Comparative Genomic Hybridisation (Array-CGH) Detects Submicroscopic Chromosomal Deletions and Duplications in Patients with Learning Disability/Mental Retardation and Dysmorphic Features', Journal of Medical Genetics, 41 (2004), 241-8.

${ }^{80}$ These attitudes are consistent with the distinction, depending on the practitioner's specialisation, that Monique Membrado proposed between 'attentive to the request' and 'regulatory' in her ethnographic analysis of a PND team in the late 1970s. Membrado, op. cit. (note 15).
} 
While it had not created any real homogeneity in practices, the new framework, in particular the obligation to collectively discuss decisions and to account for one's activity, had led to a major change in practices for everyone concerned. Decisionmaking had de facto been removed from the doctor-patient encounter and took place in teams; and the latitude allowed to practitioners was no longer individual, but collective. The differences between the centres seem to demonstrate, within the regulatory and standardised framework proper to 'therapeutic modernity', the capacity of foetal medicine to preserve the varying sensibilities that have traversed its history. The identities of the centres, which have been developed over the long term under the influence of charismatic leaders, have replaced what used to be personal standpoints. Hence the non-mainstream attitude of the Paris centre, might find legitimacy in its rejection of a logic of choice that was based on the modern Western conception of a rational, responsible and autonomous individual, ${ }^{81}$ and was particularly unsuited to the women from underprivileged and often migrant backgrounds who made up the majority of its patients. As for the form of discussions in the provincial centre, it may well stem from a strategy to protect practitioners who, with no safety net, gave their opinions in an open space over whose boundaries they had no control.

The law has taken the differences between centres into account; it is not designed to require all practitioners to share the same sensitivities and opinions. It states that 'each CPDPN is responsible for its own opinions and maintains its autonomy of assessment' with women being able to ask another centre in cases where an MTP is refused. ${ }^{82}$

Yet while the preservation of a centre's autonomy would appear to explain differences (that vary by a factor of almost two) in the number of MTP authorisations for an indication of foetal malformation, it is interesting to note the minimal impact that these differences have with regard to the population as a whole. Indeed, compared to other regions of Europe, PND practices in France are extremely effective. The detection rate of Down syndrome is among the highest, as is the proportion of affected fotuses aborted. ${ }^{83}$ Above and beyond the medical, scientific and technical skills of the practitioners, this is due to the efficiency of the health system insurance in France. The autonomy of the centres, like that of the women and couples, while it respects singular choices, does not hinder - or even helps - the propagation of a 'new eugenics' that is unrestrictive, 'pro-choice, gentle, liberal and democratic'. ${ }^{84}$ In this situation, it was not necessary to impose homogeneous practices on practitioners, or direct women's decisions. To explain this phenomenon, the concept of biological citizenship is here useful. It could be applied to both couples and practitioners and is conceived of as being 'modes of subjectification in individuals ... (that) can be explained as individual way of internalising the discourse of life and health, thereby acting responsibly in relation to questions about life and health'. ${ }^{85}$

\footnotetext{
${ }^{81}$ Mol, op. cit. (note 5).

82 Decree relating to recommendations for good PND practice (JORF no. 0133 of 11 June 2015, 9630).

${ }^{83}$ Sources Eurocat: http://www.eurocat-network.eu/prenatalscreeninganddiagnosis/prenatal\%20detection(pd) rates. The MTP rate for Down syndrome is close to 80 per cent in France, varies between 51 per cent and 62 per cent in the UK, depending on the region, stands at 54 per cent in the Netherlands and is below 50 per cent in Norway.

${ }^{84}$ Pierre-André Taguieff, 'Au cœur du raisonnement galtonien: le paradoxe de la politique malthusienne et sa solution eugéniste', Raisons Politiques, 26, 2 (2007), 175-215.

85 Björkman and Tunlid, op. cit. (note 19), 341.
} 